\title{
The Rise of Mass Consumption Societies
}

\author{
by \\ Kiminori Matsuyama \\ Department of Economics, Northwestern University
}

Contents:

Abstract

1. Introduction

2. The Model

3. Some General Properties

4. The Case of $j=1$

5. The Case of $j=2$

7. Concluding Remarks

Figures

References

DEDPS 23

November 2000
The Suntory Centre

Suntory and Toyota International Centres for Economics and Related Disciplines

London School of Economics and Political Science Houghton Street London WC2A $2 \mathrm{AE}$ Tel: (020) 79556674

* This paper had such a long gestation lag (more than ten years) that I cannot remember who should be given the credits for some of the ideas discussed here. Much of the writing was done in the spring of 1999, during my visit to the London School of Economics, whose hospitality is greatly acknowledged. I would also like to thank Gadi Barlevy, Joel Mokyr, and seminar participants at LSE, NYU and Northwestern for their comments on the previous versions. 


\begin{abstract}
This paper develops a model to understand mechanisms behind the rise of mass consumption societies. The development process depicted in the model follows the Flying Geese pattern, in which a series of industries takes off one after another. As productivity improves in these industries, each consumer good becomes affordable to an increasingly large number of households, which constantly expand the range of goods they consume. This in turn generates larger markets for consumer, goods which leads to further improvement in productivity. In order for such two-way causality to generate virtuous cycles of productivity gains and expanding markets, income distribution should be neither too equal nor too unequal. Some income inequality is needed for the economy to take off; too much equality means that the economy stagnates in a poverty trap. With too much inequality, the economy's development stops prematurely. The rise of a mass consumption society is thus an essential element for sustainable development.
\end{abstract}

Keywords: Income distribution; mass consumption society; industry-specific learning-by-doing; endogenous technological changes; nonhomothetic preferences; demand complementarity; necessities and luxuries; trickle-down and trickle-up mechanisms; the domino effect; flying geese pattern; cooperative dynamical systems.

JEL Nos.: O11, O12, O33.

(C) Kiminori Matsuyama. All rights reserved. Short sections of text, not to exceed two paragraphs, may be quoted without explicit permission provided that full credit, including (c) notice, is given to the source. 


\section{The Rise of Mass Consumption Societies}

"The past few decades have seen the rise, here in America, of a new and unique phenomenon in human history, the mass consumption society."

George Katona, The Mass Consumption Society (1964)

\section{Introduction.}

Roughly speaking, the mass consumption society can be defined as a society, where not a few individuals, nor a thin upper class, but the majority of families enjoys the benefits of increased productivity and constantly expands their range of consumer goods. Many authors have described the mass consumption society as a relatively new phenomenon in human history. Katona (1964) wrote, for example,

"Throughout the course of human history, poverty has been the rule, riches the exception. Societies in the past were called affluent when their ruling classes lived in abundance and luxury. Even in the rich countries of the past, the great majority of people struggled for mere subsistence. Today in this country minimum standards of nutrition, housing, and clothing are assured, not for all, but for the majority. Beyond these minimum needs, such former luxuries as homeownership, durable goods, travel, recreation, and entertainment are no longer restricted to a few. The broad masses participate in enjoying all these things and generate most of the demand for them." (italics added)

Although Katona stressed that this is a phenomenon unique to the American society, virtually all the industrialized countries have gone 
through similar transformation after WWII. ${ }^{2}$ Rostow (1960), in developing his thesis of stages of economic growth, named the last of the five stages, "the age of high mass consumption." He argued that not only the United States, but also Canada, Australia, Western European countries, and Japan had reached this stage. Fourastié (1979) discussed similar development in postwar France, from 1946 to 1975, the period that many French writers call Les Trente Glorieuses (The Glorious Thirty Years) after the title of his book. Many Japanese also commented on a new feature of postwar booms in the fifties and sixties; Contrary to the prewar booms, which were mostly driven by military demand, they were driven, or at least supported, by consumer demands, particularly for home electronic appliances. ${ }^{3}$

One piece of the evidence that these authors routinely present is the penetration rates of consumer goods. Figure 1 illustrates the typical pattern in a stylized way. Each curve shows the fraction of households

\footnotetext{
${ }^{2}$ Some historians argue that Katona also overstated the extent to which mass consumption is a modern phenomenon. For example, Joel Mokyr suggested, in his personal communication to me, that "there are other societies in which ownership and consumption of much of what society has to offer was pretty widespread," and cited the example of the so-called consumer revolution in the seventeenth century Dutch Republic, as described by Schama (1987). This raises some interesting questions. Was mass consumption a merely consequence of the Dutch Republic's prosperity, or did mass consumption help the Dutch Republic to prosper? Why did it happen in the Dutch Republic, not in the other parts of Europe? The model presented below should provide a useful conceptual framework for addressing these questions.

${ }^{3}$ For the description of Japanese postwar booms and Shoh-hi-kaku-mei (The Consumption Revolution), see Kosai and Ogino (1980) and Uchino (1978). In the late fifties, a TV set, a washing machine, and a refrigerator were by far the most frequently named items in consumer surveys of housewives as what they would want to purchase, to the extent that the media called them, San-shu-no-jin-gi, after the three holy goods used when a new emperor of Japan is crowned. In the mid sixties, a car, an air-conditioner, and a color TV set achieved similar status of dreamed items that they were sometimes referred as New San-shu-no-jin-gi, and sometimes as 3C (because a Japanglish word for "air-conditioner" was "cooler.") It was the markets for these products that grew most rapidly during the period up to the first oil crisis.
} 
using a particular consumer good. For example, the use of vacuum cleaners, washing machines, telephones, was restricted to a small section of the population before WWII, but spread to the low-income households during the fifties and sixties. Many other consumer goods, such as television sets, cars, and air-conditioners follow similar paths, with some lags. ${ }^{4}$ This pattern is so similar across many industrialized countries that the penetration rates of representative goods have become the popular yardstick for comparing the standards of living across societies. One key feature of this pattern is that not only the market for each consumer good takes off, but also each takeoff is followed by one after another. The pattern shown in Figure 1 will be called "Flying Geese" in this paper. ${ }^{5}$

As many countries have experienced this transformation, the very notion of necessities and luxuries has changed. Many consumer goods that have penetrated into the majority of households, such as vacuum cleaners, washing machines, telephones, televisions, refrigerators, automobiles, airconditioners, are now generally regarded as necessities in rich societies,

${ }^{4}$ In order for the penetration rates to be increasing, "a good" must be defined sufficiently broadly, so that a new product is treated as the same good with old ones, if it essentially performs the same function with better quality. This means not only that different generations of vacuum cleaners or of washing machines should be grouped together. It also means that black-and-white and color televisions, or record players and CD players should be grouped together. If the penetration rates of different vintages of such a broadly defined good were plotted, they would exhibit hump-shaped curves, as each generation of a good replaces an old one, only to be replaced by a new one. This pattern of product growth and obsolescence is an interesting issue and has previously been analyzed by Stokey (1988) and many others, but it is not the subject of this paper.

${ }^{5}$ The metaphor of flying geese was previously used by Akamatsu (1961), who referred to the inverse-V shape of the time series for the imports, domestic production, and exports of manufacturing goods. This pattern is now more commonly called "Product Cycles." 
and yet, they were all considered as luxuries only a half century ago. To quote Katona again,

"We are rich compared with our grandparents and compared with most other peoples of the world. In fact, however, we are still a middle-class society, enjoying middle-class comforts. .... The drudgery of seeking subsistence has been supplanted for millions of people, not by abundance and indulgence, but rather by a new concept of what are necessities and needs." (italics added)

The notion of necessities and luxuries not only has changed over time. It also varies from countries to countries. Many goods that are taken for granted in rich countries remain luxuries in many parts of the world. The question of why some countries have failed to become mass consumption societies is at least as important as the question of why some succeeded.

This paper develops a model, which is consistent with the key features of mass consumption societies described above, and then uses it to understand the mechanisms behind the rise of mass consumption societies, and to identify the conditions under which a country succeeds in making such transformation. What is central to the analysis is a two-way causality between productivity improvement and the rise of a mass consumption society. As productivity improves, the prices of consumer goods go down, and they become affordable to an increasingly large number of households. 
This in turn generates larger markets for these goods, which induce further improvement in productivity, creating a virtuous circle of productivity gains and expanding markets. Or the two-way causality may mean that the economy stagnates because the lack of productivity gains and the lack of markets reinforce each other.

In the model developed below, the households differ only in their income. They have the identical, nonhomothetic preferences, which have the property that they have well-defined priority over the space of consumer goods. As their income levels go up, they expand the range of consumer goods they purchase, instead of purchasing more of the same goods that they already consume. This has several important implications. First, the market size for each good depends not on the aggregate income, but on the number of households that can afford it. Second, when the prices of high priority goods go down, demand for less priority goods go up. That is to say that there exist demand complementarities from high priority goods to low priority goods. As the expense for essential items decline, less essential items become affordable, which allows the households to move down further on their shopping list. Third, the very notion of necessities and luxuries is a relative one. Each consumer good is a luxury good for poor households, but a necessity for rich households. As a household's income goes up, a consumer good changes from a luxury to an amenity, and finally, a necessity. On the technology side, there is industry-specific learning-by-doing, which represents dynamic increasing returns in each 
consumer goods industry. No interindustry spillover of learning-by-doing is assumed.

The dynamic evolution of this model economy is described by a cooperative dynamical system, and displays the following features. First, the penetration rates of consumer goods show the "Flying Geese" pattern. A series of consumer goods industries takes off one after another, even though there is no inter-industry spillover of learning-by-doing. The intuition behind this pattern is easy to grasp. The purchase of a good by the high-income households reduces its price, which makes this good affordable to the low-income households, which were previously unable to purchase it. This trickle-down process helps an industry to take off. However, this is not the end of the story. The purchase of a good by the low-income households, by pushing down its price even further, helps to reduce the expense of the high-income households. This allows them to purchase the next item on their shopping list. Through this trickle-up process, productivity gains in one industry lead to productivity gains in the next.

Second, the set of steady states is a lattice, and the economy grows monotonically until it converges to the least element of the lattice. That is, if there are multiple steady states, the economy is trapped into the lowest steady state, where a relatively small fraction of the households consumes 
a relatively small set of the goods. Thus, there is the possibility that the trickle-down and trickle-up processes are interrupted.

Third, the dynamic evolution of the economy depends critically on income distribution. Some income inequality is needed for the economy to take off; with too much equality, the economy stagnates in a poverty trap. This is because, in order to trigger the process, the economy needs a critical mass of the rich households, which can afford to buy some goods, even when they are still expensive. With too much inequality, on the other hand, the process stops prematurely. This is because neither trickle-down nor trickle-up mechanisms would work if there are too much income gaps. To put it another way, the rise of a mass consumption society requires income to be distributed in certain ways. Because of this, the effects of income transfer also turn out to be subtle. Perhaps the analogy of the dominos may be useful. In order for the dominos to continue falling like a cascade, they need to be spaced appropriately. If they are put tightly together, the dominos cannot fall. If there is a big gap between dominos, a falling domino cannot knock down the next one, hence the chain reactions will be interrupted.

It is worth emphasizing that the model developed in this paper explains the Flying Geese pattern based on endogenous technological changes. One might be tempted to argue that we observe the Flying Geese pattern simply because different consumer goods were invented at different times. Such 
an explanation based on exogenous technological progress has a couple of problems. First, while the penetration rates of consumer goods display similar patterns across many developed countries, their timings are different across countries. Indeed, these goods hardly have penetrated in many underdeveloped countries. Second, many consumer goods, such as vacuum cleaners, washing machines, telephones, radios, televisions, automobiles, were invented by the early twentieth century in their most primitive forms. Only through further improvement, these goods have become affordable to the majority of the households in developed countries. And the market size is one of the critical factors determining the speed of such improvement. This is not to deny the possibility that some major technological advances that were applicable to many industries, such as electric motors or Taylorism, were responsible for making the rise of mass consumption societies possible for the first time in human history. Any theory based on exogenous technological events, however, cannot explain why the United States led the way in becoming the mass consumption society nor why certain goods spread faster than others.

There are some closely related studies in the literature. Baland and Ray (1991) and Murphy, Shleifer, and Vishny (1989) both studied models of increasing returns and nonhomothetic preferences and explored how income distribution affects development through demand composition effects. In Baland and Ray, the notion of a necessity and a luxury is an 
absolute one, and they demonstrated that redistributing from the rich who consumes a luxury, to the poor who cannot consume enough necessities, may reduce unemployment. Murphy, Shleifer and Vishny used preferences similar to this paper, and showed how income distribution affects the two-way causality between productivity gains and expanding markets through the profit multiplier in a monopolistic competition model of technology adoption. Both models are static, and hence do not generate the Flying Geese pattern. Matsuyama (1991a) showed how a productivity improvement in agriculture spills over to manufacturing through demand complementarity. With a lower price of food, the households can afford to buy the manufacturing good, which stimulates learning-by-doing in manufacturing. There is only one manufacturing good, so that the model does not generate the Flying Geese pattern. Furthermore, income distribution plays no role in that model.

Before proceeding, it is worth pointing out what this paper is not about. Most work that followed Katona's contribution came from the behavioral science literature, which put emphasis on sociological and psychological aspects of mass consumption societies. They discuss the importance of mass-psychology, "conspicuous consumption," the desire of consumers to "keep up with Joneses," their inability to "make ends meet," and the attempts by big businesses to manipulate the formation of the mass consumer culture, etc. In the model presented below, all the households have the identical, non-interdependent preferences, are perfectly informed 
of all the goods available, and faced with well-defined budget constraints. Therefore, the present paper has nothing to say about these aspects of mass consumption societies.

The rest of the paper is organized as follows. Section 2 sets up the model, and derives the dynamical system governing the evolution of the economy. Section 3 discusses some general properties of the system. Sections 4 and 5 look at special cases to examine in detail the roles of income distribution. Section 6 discusses alternative specifications of the model. Possible extensions are discussed in the concluding section.

\section{The Model.}

This section describes the structure of the economy and derives the system that governs the dynamic trajectory of the economy. Many assumptions discussed below are adopted to simplify the exposition, and can be relaxed or replaced by alternative assumptions, as will be explained in Section 6 .

The economy is populated by a continuum of households with the unit measure. They supply labor, and consume some goods and leisure. Goods are produced by labor only. The detailed descriptions of the model are now given, first the preferences, then income distribution, and finally technologies. 


\subsection{Goods and Preferences:}

There are $J+1$ goods, labeled $j=0,1, \ldots, J$. Good zero is food; it is a homogenous, divisible good. In addition, there are J manufacturing goods, indexed as $j=1, \ldots, J$. They are indivisible and come in discrete units. All the households have the same preferences, given by the following utility function:

$$
\text { c if } c \leq 1
$$

$$
\begin{aligned}
& \mathrm{U}= \\
& 1+\sum_{k=1}^{J}\left(\prod_{j=1}^{k} x_{j}\right)+\eta l \quad \text { if } c>1
\end{aligned}
$$

where $c$ is food consumption, $l$ is the leisure, and $x_{j}$ is an indicator function, with $x_{j}=1$ if manufacturing good $j$ is consumed and $x_{j}=0$ if it is not. Food is a necessity, and the household needs to consume a minimum amount of food, the subsistence level, before consuming any manufacturing good. The subsistence level is normalized to be one to ease the notational burden. It is also assumed, for the sake of simplicity, that the propensity to spend on food is equal to zero above the subsistence level. The preferences over manufacturing goods have the property that the households benefit nothing from consuming good $k$, if $x_{j}=0$ for some $j$ $<k$. This implies that the households consume good $k$, only if they also 
consume all the manufacturing goods, whose indices are less than $k$. In other words, the households have a well-defined priority over the set of manufacturing goods, with a lower indexed good is higher on their shopping list. What is also implicit in the preferences is that the household's demand for each manufacturing good satiates after one unit.

It is worth emphasizing that neither the strong form of Pareto-Edgeworth complementarities nor the assumption that all the households have the same ordering are essential in the following analysis: see sections $6 \mathrm{~B}$ and 6C for more detailed discussion. What is essential is that the households do not change their orderings, when the relative prices change. As long as the range of relative price movements is appropriately restricted, much of the results would carry over for a broad class of preferences. The above specification is convenient only because it eliminates the need for restricting the range of relative price movements. ${ }^{6}$

\footnotetext{
${ }^{6}$ Note that lexicographic preferences would not work for this purpose. The households have lexicographic preferences over the manufacturing goods, if they always prefer having good $j$ than not having good $j$, independent of their consumption of higher indexed goods. This does not mean, however, that they always buy good $j$ before good $k>j$. This is because they prefer having good $k$ than not having good $k$, given that they don't have good $j$. Therefore, the households may end up consuming good $k>j$ without consuming good $j$. This happens when the households cannot afford good $j$, but can afford good $k>j$. In the specification adopted here, they buy leisure instead of $\operatorname{good} k>j$ if they cannot afford good $j$.
} 


\subsection{The Budget Constraint and Individual Demand:}

The budget constraint for the household with income $I$ is $p_{0} c+\sum_{j=1}^{J} p_{j} x_{j}+l \leq I$, where $p_{0}$ is the price of food, $p_{j}$ is the price of manufacturing good $j$, with leisure being taken as the numeraire. ${ }^{7}$ Because of the well-defined priority over the manufacturing goods, the household's consumption problem can thus be simplified as: to choose $c, k$, and $l$ to maximize:

$$
\begin{aligned}
& \text { c if } c \leq 1 \text {, } \\
& U= \\
& 1+k+\eta l \quad \text { if } c>1
\end{aligned}
$$

subject to the budget constraint, $p_{0} c+\sum_{j=1}^{k} p_{j}+l \leq I$.

Throughout the paper, it is assumed that the marginal utility of leisure is sufficiently small that $\eta p_{j}<1$ for all $j=1,2, \ldots, J$. This means that the households purchase as many goods as possible from the top of their shopping list. Thus, the consumption demand of each household takes the following form:

\footnotetext{
${ }^{7}$ As seen later, the prices do depend on time, as productivity changes over time. Time is suppressed, however, to minimize the notation, until needed. Three additional assumptions are also implicit in this formulation of the household's problem. First, there is no saving and borrowing. Second, there is no intertemporal substitution of consumption. Third, households cannot set up lotteries. Introducing these factors would only obscure the basic
} 


$$
\begin{aligned}
& \begin{array}{l}
I<P_{0} \\
P_{k} \leq I<P_{k+1}(k=0, \ldots, J-1) \quad \Rightarrow c=I / P_{0}, l=0, x_{j}=0(j=1, \ldots, J), \\
k+1, \ldots, J), \\
I \geq P_{J}
\end{array} \quad \Rightarrow c=1, l=I-P_{k}, x_{j}=1(j=1, \ldots, k), x_{j}=0 \quad(j= \\
&
\end{aligned}
$$

where $P_{k}=\sum_{j=0}^{k} p_{j}$ can be interpreted as the minimum level of income that induces the household to consume manufacturing good $k$.

The most important feature of the individual demand curve derived above is that an additional income translates into an additional demand for a manufacturing good, only when it pushes the household's income above the critical level of income. If the household's income level is well below $P_{j}$ , an additional income would be spent on food, leisure, or manufacturing goods with lower indices. For the poor, good $j$ remains a luxury, which is beyond their means. If the household's income level exceeds $P_{j}$, on the other hand, an additional income would be spent on leisure, or manufacturing goods with higher indices. For the rich, good $j$ is a necessity, with which they are already satiated. What is essential for the following analysis is that the marginal propensity to spend on a manufacturing good is small when income is either very low or very high. 
This property of demand captures the following idea. A manufacturing good is a luxury for many at a lower level of economic development. As the economy develops and an overall level of income grows, it changes from a luxury to an amenity, and then to a necessity. In other words, the very notion of what is a luxury and what is a necessity changes with income. ${ }^{8}$

\subsection{Income Distribution and Aggregate Demand}

Having derived individual demand curves, the next step is an aggregation. Let $F$ be the distribution of income across households, i.e., $F(I)$ is the fraction of the households, whose income is less than or equal to I. Income differs across the households due to skill differences, reflected in differences in the effective labor supply. The total labor supply is thus equal to $L=\int_{0}^{\infty} I d F(I) .^{9}$

${ }^{8}$ Here, "a necessity" is defined as a good, whose share in the household expenditure goes up when the household income declines. "A luxury" is defined a good whose share in the household expenditure goes up when the household income increases sufficiently. The qualifier "sufficiently" is needed because of the discreteness of a good. If a household cannot afford to buy an air-conditioner, it cannot afford to buy it even when its income goes up infinitesimally. The definition of a necessity (luxury) commonly found in textbooks, i.e., a good, whose income elasticity of demand is less (greater) than one, is not appropriate in the present model, because this definition assumes the divisibility of goods and deals only with an infinitesimal change in income.

${ }^{9}$ Since the households generally consume leisure, one may want to call $I-l$ "(labor) income" instead, in which case $I$ may be called "the purchasing power" of the household. Needless to say, this is purely a matter of semantics, and none of the analysis would be affected. 
The income is the only source of heterogeneity across the households. Since only the households, whose income is higher than $P_{j}=\sum_{i=0}^{j} p_{i}$ purchase a manufacturing good $j$, and no household purchases more than one unit of any manufacturing good, the aggregate demand for good $j$ is equal to the mass of the households, whose income is higher than $P_{j}$ :

(1) $C_{j}=1-F\left(P_{j}\right)=1-F\left(\sum_{i=0}^{j} p_{i}\right)$.

$$
(j=1, \ldots, J)
$$

Many features of the aggregate demand functions, eq. (1), deserve emphasis. First, it depends on income distribution, because the marginal propensity to spend on a manufacturing good varies with the household income. Second, it is bounded from above by one. This is because the size of the market for a manufacturing good is limited by the number of households that can afford to consume it, not by the aggregate income of the economy. Third, a decline in the price of good $i$ does not affect the demand for good $j<i \quad\left(C_{j i}=\partial C_{j} \partial \partial p_{i}=0\right)$, while it generally increases the demand for good $j \geq i\left(C_{j i} \geq 0\right)$. In other words, demand complementarity (in the sense of Hicks-Allen) exist from a lower indexed good to a higher indexed good, but not the other way around. This is because of the asymmetric way in which the income effect of price changes operates. A decline in the price of good $i$ only affects the households, whose income is higher than $P_{i}$, and these households may respond by spending the 
increased real income on higher indexed goods, but never on lower indexed ones. Fourth, the aggregate demand for manufacturing goods is decreasing in indices, $C_{1} \geq C_{2} \geq \ldots \geq C_{\mu}$, because all the households have the same priority across these goods.

\subsection{Technologies.}

All the goods are produced in competitive industries with constant returns to scale technologies. Producing one unit of food requires $a_{0}$ units of labor, which is constant over time. Labor productivity in manufacturing industries can improve, because of an industry-specific learning-by-doing. More specifically, producing one unit of manufacturing good $j$ as of time $t$ requires $a_{j}(t)=A_{j}\left(Q_{j}(t)\right)$, where $A_{j}(\bullet)$ is a decreasing function, and $Q_{j}(t)$ is the discounted cumulative output of industry $j$, given by

(2) $\quad Q_{j}(t) \equiv \delta_{j} \int_{-\infty}^{t} C_{j}(s) \exp \left[\delta_{j}(s-t)\right] d s \leq 1$,

$(j=1, \ldots, J)$

where $\delta_{j}>0$. The idea is that each industry learns to produce more efficiently, as it accumulates more manufacturing experiences. Furthermore, producers do not take into account these learning effects when choosing their output, as they are external to them. The parameter $\delta_{j}$ may be interpreted both as the speed of learning in industry $j$ and as the 
depreciation rate of learning experiences. To see this, differentiating the above expression with respect to $t$ yields

(3) $\dot{Q}_{j}(t)=\delta_{j}\left\{C_{j}(t)-Q_{j}(t)\right\}$.

$(j=1, \ldots, J)$

where the dot indicates the time derivative. Note also that the depreciation keeps $Q_{j}(t)$ from growing unbounded. Indeed, as seen in (2), it is bounded from above by one, because $C_{j}(t)$ is bounded from above by one.

What is important here is the assumption that there exist some forms of dynamic increasing returns in each consumer goods industry. Learningby-doing in production is adopted here because it is the simplest (and perhaps most standard) way of modeling dynamic increasing returns. It is also worth pointing out that there is an alternative interpretation of eqs. (2) and (3): learning-by-doing in consumption. The "price" of a consumer good that the household must pay includes not only the price charged by the producers, but also the effort required by the household to use the good. As more households accumulate experiences, the required amount of effort will decline, thereby reducing the effective price of the good, measured in leisure. Such dynamic consumption externalities would be isomorphic to learning-by-doing in production in the present model. The distinction between these two forms would be critical in an open economy (see Section 7). 


\subsection{The Dynamical System.}

We are now ready to derive the dynamical system that describes the law of motion governing the trajectory of the economy. First, note that perfect competition in each industry ensures that the price of each good is equal to the marginal (and average) cost, which is nothing but the unit labor requirement. (Recall that labor is the numeraire). Therefore, we have

(4) $\quad p_{0}=a_{0}$ and $p_{j}(t)=A_{j}\left(Q_{j}(t)\right)$

$$
(j=1, \ldots, J)
$$

Inserting (4) into (1) yields

(5) $\quad C_{j}(t)=\quad 1-F\left(a_{0}+\sum_{i=1}^{j} A_{i}\left(Q_{i}(t)\right)\right) \equiv D_{j}(Q(t))$,

where $Q=\left(Q_{1}, Q_{2}, \ldots, Q_{J}\right) \in[0,1]^{J}$. Let $D(Q) \equiv\left(D_{1}(Q), D_{2}(Q), \ldots, D_{J}(Q)\right)$. Note that $D_{i j}=\partial D_{i} \partial Q_{j}=0$ for all $i<j$ and $D_{i j} \geq 0$ for all $i \geq j$ due to the (asymmetric) demand complementarity. Therefore, the mapping, $D$ : $[0,1]^{J} \rightarrow[0,1]^{\prime}$, is increasing in that $Q^{\prime}-Q \in \Re_{+}^{J}$ implies $D\left(Q^{\prime}\right)-D(Q) \in \Re_{+}^{J}$, where $\Re_{+}^{J}$ is the set of $J$-dimensional nonnegative vectors. 
Inserting (5) into (3) yields

(6)

$$
\dot{Q}_{j}(t)=\delta_{j}\left\{D_{j}(Q(t))-Q_{j}(t)\right\} \equiv \Psi_{j}(Q(t))
$$

$(j=1, \ldots, J)$

which can be expressed in a more compact manner, as follows:

$\dot{Q}=\Psi(Q)$

where $\Psi=\left(\Psi_{1}, \Psi_{2}, \ldots, \Psi_{\digamma}\right):[0,1]^{J} \rightarrow \Re^{J}$ is a vector field on $[0,1]^{J}$.

One feature of this dynamical system is worth emphasizing. In a steady state, the value of $Q_{j}$ is equal to the fraction of the households that consume good $j$. This feature of the system makes the following results easy to interpret.

\section{Some General Properties.}

One major advantage of the present model is that it has many general properties that hold true for an arbitrary number of industries, which are discussed in this section. A few words of caution should be made here. First, different properties discussed below require different degrees of regularity conditions, which will not be stated for the sake of the simplicity and clarity of presentation. Second, some basic terminologies of the 
dynamical system theory will not be formally defined. Only the intuitive meanings are stated. The reader interested in formality should consult a standard textbook of the dynamical system theory. Third, the reader not interested in generality may want, at least at first reading, to skim through the rest of this section and to move onto the subsequent sections, where the low dimensional cases, $J \leq 2$, are discussed in detail.

(P1): $[0,1]^{\prime}$ is positively invariant.

This property merely states that, if the economy starts in $[0,1]^{I}$, the economy remains in $[0,1]^{I}$ forever, and hence the system can describe the trajectory for the entire future. To see why (P1) is true, note from eq. (6) that $Q_{j}=0$ implies $\Psi_{j}(Q) \geq 0$, and that $Q_{j}=1$ implies $\Psi_{j}(Q) \leq 0$. In other words, the vector field always points inward at the boundary of $[0,1]^{I}$, so that the trajectory cannot escape $[0,1]^{\prime}$.

(P2): $\Psi_{i j} \equiv \partial \Psi_{i} / \partial Q_{j}=0$ if $i<j ; \Psi_{i i}=\delta_{i}\left(D_{i i}-1\right) ; \Psi_{i j}=\delta_{i} D_{i j} \geq 0$ if $i>j$.

The dynamical system is thus recursive and cooperative. It is recursive in that the dynamics of $\left(Q_{1}, \ldots, Q_{j}\right)$ is independent of that of $\left(Q_{j+1}, \ldots, Q_{J}\right)$ for all $j$. The reason for this is asymmetry in which demand complementarity operates in this economy. As one industry improves its productivity and its cost and output price declines, only the industries with higher indices 
see demand for their goods increase. The resulting increase in output leads to a faster learning only in these industries. The system is also cooperative in the sense of Hirsch (1982), that is $\Psi_{i j} \geq 0$ for all $i \neq j$. The system is cooperative because productivity improvement and the resulting price reduction in one industry may increase but never reduces demand in other industries.

It should be noted that the mechanism through which productivity improvement spillovers from an industry with a lower index to an industry with a high index is demand complementarity. In the present model, all the learning-by-doing effects are industry-specific. An industry learns nothing from manufacturing experiences of other industries.

Let $\Re_{++}^{J}$ denote the set of $J$-dimensional vectors with positive components.

(P3): $M_{+} \quad \equiv\left\{Q \in[0,1]^{J} \mid \Psi(Q) \in \mathfrak{R}_{+}^{J}\right\} \quad=\left\{Q \in[0,1]^{J} \mid D(Q)-Q \in \mathfrak{R}_{+}^{J}\right\}, \quad M_{++} \equiv$ $\left\{Q \in[0,1]^{J} \mid \Psi(Q) \in \Re_{++}^{J}\right\} \quad=\left\{Q \in[0,1]^{J} \mid D(Q)-Q \in \Re_{++}^{J}\right\}, \quad M_{-} \equiv\left\{Q \in[0,1]^{J} \mid-\Psi(Q) \in \Re_{+}^{J}\right\}$ $=\left\{Q \in[0,1]^{J} \mid Q-D(Q) \in \mathfrak{R}_{+}^{J}\right\}$, and

$M_{-} \equiv\left\{Q \in[0,1]^{J} \mid-\Psi(Q) \in \mathfrak{R}_{++}^{J}\right\}=\left\{Q \in[0,1]^{J} \mid Q-D(Q) \in \mathfrak{R}_{++}^{J}\right\}$ are positively invariant.

That is, $\dot{Q}(s) \in \Re_{+}^{J}\left(\Re_{++}^{J}\right)$ implies $\dot{Q}(t) \in \Re_{+}^{J}\left(\Re_{++}^{J}\right)$ for all $t \geq s$, and $-\dot{Q}(s) \in \Re_{+}^{J}\left(\Re_{++}^{J}\right)$ implies $-\dot{Q}(t) \in \Re_{+}^{J}\left(\Re_{++}^{J}\right)$ for all $t \geq s$. This is another 
property of a cooperative system, which maintains the monotonicity of trajectories. See Smith (1995, Proposition 3.2.1). Roughly speaking, it means that all the industries move together.

(P4): The set of steady states, $S \equiv\left\{Q \in[0,1]^{J} \mid \Psi(Q)=0\right\}=\left\{Q \in[0,1]^{J} \mid Q=D(Q)\right\}$, is a nonempty, compact lattice, where the ordering is induced by $\Re_{+}^{J}$. The greatest element of $S$ is $\sup M_{+}$and its least element is $\inf M_{-}$.

This follows from applying Tarski's (1955) fixed-point theorem to $D$ : $[0,1]^{\prime} \rightarrow[0,1]^{J}$. A lattice is a partially ordered set, which contains both the least upper bound and the greatest lower bound of any pair of its elements. One important feature of a lattice is that, if it is compact, it contains both its greatest and least elements.

(P5): For any initial condition, $Q(0) \in[0,1]^{J}, \lim _{t \rightarrow \infty} Q(t) \in S$.

Thus, the system is globally convergent; the economy converges to a steady state without any exception. To understand this, note first that any onedimensional dynamical system is globally convergent. Since the dynamics of $Q_{1}$ is independent of the rest of the system (the recursiveness), it can be viewed as a one-dimensional system, hence it converges globally. This effectively reduces the dimensionality of the system by one. Repeating this process shows that the global convergence of the entire dynamics. It is also worth pointing out that, even without recursiveness, a cooperative system 
is globally convergent if $J \leq 2$ (Smith 1995, Theorem 3.2.2). If $J \geq 3$, cooperativeness implies that the trajectory converges to a steady state, for almost all the initial conditions under the regularity condition called irreducibility (Smith 1995, Theorem 4.1.2).

(P6): If $Q(0)=(0,0, \ldots, 0), Q(t) \in M_{+}$for all $t>0$, and $\lim _{t \rightarrow \infty} Q(t)=\inf M_{-}$, the least element of $S$.

The first part follows from $Q(0)=(0,0, \ldots, 0) \in M_{+}$and the positive invariance of $M_{+}$. The second part then follows from (P4). Note that (P6) does not require recursiveness.

The first part of (P6) states that, if the economy starts with very little manufacturing experiences, all the industries grow monotonically in productivity. Since $C_{j}=D_{j}(Q)$ is increasing in $Q$ for all $j$ and $C_{1} \geq C_{2} \geq \ldots \geq C_{J}$, the dynamics, if it starts sufficiently close to $(0,0, \ldots, 0)$, show the Flying Geese pattern.

The second part of (P6) implies that the monotone growth of industries may stop prematurely and the economy may fail to develop to reach its full potential. If $S$ contains more than one element, the economy will be trapped into the lowest of them. In this case, a relatively small fraction of households is able to enjoy a relatively small number of consumer goods. 
In other words, a larger fraction of households would enjoy a larger number of consumer goods in every other steady state.

(P7): If $Q^{*} \in S$ is an isolated, unstable steady state, there exists a monotone increasing heteroclinic orbit from $Q^{*}$, which converges to the least element of $\left\{Q \in S \mid Q-Q^{*} \in \Re_{+}^{J}\right\}$ and a monotone decreasing heteroclinic orbit from $Q^{*}$, which converges to the greatest element of $\left\{Q \in S \mid Q^{*}-Q \in \Re_{+}^{J}\right\}$. These orbits are tangent at $Q^{*}$ to the eigenvector associated with the stability modulus of $Q^{*}$.

Figure 2 illustrates (P7), which can be proved under the irreducibility condition (Smith 1995, Theorem 4.3.3). A unstable steady state is sandwiched by two stable steady states, one from "above" and one from "below," and the flow of this J-dimensional dynamics around unstable steady states behaves as in a one-dimensional system. In other words, there is a sense in which stable and unstable steady states exist alternately.

In summary, the dynamics of this economy show the Flying Geese pattern, in which a series of industries take off one after another. How high they can fly, however, depends critically on the structure of the economy. There may be multiple steady states, and, in that case, the economy will converge to the lowest of them. Even if the steady state is unique, its level may be low, leaving most consumer goods unaffordable to the majority of 
households. In other words, the economy may fail to transform itself to a mass consumption society. Some important questions need to be addressed. What determines the structure of $S$ ? How does it depend on income distribution? What kind of redistributive policies, if any, could eliminate low-level steady states? To answer these questions, the following sections turn to the case, where a number of industries is small.

\section{The Case of $J=1$.}

Consider the case, where $J=1$. By dropping the subscript and suppressing the time, eq. (5) is simplified to

$$
\dot{Q}=\delta\{D(Q)-Q\}
$$

where $D(Q) \equiv 1-F\left(a_{0}+A(Q)\right)$ is the aggregate demand for the (only) manufacturing good, which increases with $Q$, whose exact shape depends on, among other things, income distribution, $F$. In a steady state, the fraction of the household, which consumes the manufacturing good is given by $Q^{*}=1-F\left(a_{0}+A\left(Q^{*}\right)\right)$. When the economy starts at $Q(0)=0$, it converges to the lowest of the steady states. The economy that sees the rise of a mass consumption society is the economy whose (lowest) steady state level is high. 
Generically, there is an odd number of steady states, alternating between stable and unstable ones. In Figure 3, there are three. The economy converges to the lowest and cannot develop further. In this case, a slight upward shift of the $D$ curve makes a big difference, if it eliminates the lowest of the steady states. This does not necessarily mean, however, that the economy would perform well if the steady state is unique. See Figure 4, where the two graphs, each representing the aggregate demand as a function of $Q$, are, in a way, very similar. Yet, the economy develops very differently. The basic message of Figures 3 and 4 is that even a slight exogenous change can lead to the rise of a mass consumption society in an economy, which would otherwise stagnate.

\subsection{Shifts in the D curve}

One possible way in which the $D$ curve can be shifted is a change in agricultural productivity. An decline in $a_{0}$ shifts the $D$ curve upward, because the lower price of food makes it possible for a larger fraction of the households to buy the manufacturing good. If the change is small, only a small number of households is induced to buy the good initially. However, their purchase reduces its price, which makes the next group of households buys the good, which further reduces the price, so that the next group can buy it as well. This process of a trickle-down from the higherincome households to the lower-income households can go a long way, 
even if the initial change is small. Note also that, in the case of Figure 3, even a small, temporary, agricultural boom can make a big, long-run impact. Once the economy started moving sufficiently close to the higher steady state, the reverse change would not stop the rise of a mass consumption society.

A food aid has the same effect with a decline in $a_{0}$. The above exercise thus can be viewed as an illustration for, among others, how the Marshall plan helped Western Europe to become a mass consumption society so quickly

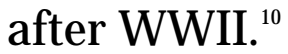

The above exercise can also be used to see the effect of one type of changes in income distribution, $F$. Note that a change in $F$ shifts the $D$ curve upward, if and only if $F$ after the change first-order-stochastically dominates $F$ before the change.

\subsection{The Effects of Income Inequality}

The effects of income inequality are much harder to analyze, because any standard measure of inequality, such as the Gini coefficient, is of no use.

\footnotetext{
${ }^{10}$ Our discussion focuses on the effect of a decline in the food price under the assumption that the economy in the lowest steady state. However, the analysis itself is entirely symmetric. Figures 3 and 4
} 
Neither is the second-order stochastic dominance. It is easy to see that mean-preserving spreads may increase or decrease the level of the lowest steady state.

Nevertheless, there is a sense in which one could say that income distribution can be neither too equal nor too unequal for virtuous circles of productivity gains and expanding markets to operate smoothly. Suppose that, under some income distribution $F$, the economy satisfies the condition, which enables it to transform to a mass consumption society to its fullest extent. That is, the lowest (and unique) steady state is $Q^{*}=1$, as shown in Figure 5a. Starting from this situation, redistribute income to equalize it completely. Then, the situation becomes Figure 5b, in which case the economy stagnates $Q^{*}=0$. With perfect equality, the process does not even begin, and the economy stagnates in a poverty trap. Some inequality is needed for the economy to take off. This is because, to trigger the process, some households have to be rich enough to be able to buy the good. Now, consider the other extreme: redistribute everything to a fraction of the households, and leave nothing to the rest. Then, the situation becomes Figure 5c. In this case, the economy develops initially, but the development stops prematurely. This is because the trickle-down 
mechanism is interrupted, if there is too much income gap. Dominos cannot continue falling, if they are spaced too apart.

\subsection{The Case of Four Classes}

To explore the effects of redistribution further, let us consider the following special case. The population is divided into four classes of households: the Rich $(R)$, the Upper-middle class $(U)$, the Lower-middle-class $(L)$, and the Poor $(P)$. The households within each class have the same level of income, which are given by $I^{R}>I^{U}>I^{L}>I^{P}$, respectively. The sizes of these classes are denoted by $n^{R}, n^{u}, n^{L}$, and $n^{p}$, respectively, which add up to one. It is also notationally convenient to define $0<N^{R}<N^{U}<N^{L}<1$ by $N^{R} \equiv n^{R}, N^{U} \equiv$ $n^{R}+n^{U}$, and $N^{L} \equiv n^{R}+n^{U}+n^{L}=1-n^{P}$.

Furthermore, to limit the number of possibilities, it is assumed that $I^{R}>a_{0}+$ $A(0)$ and $I^{P}<a_{0}+A(1)$. That is, the Rich are so rich that they can afford to buy the good, regardless of the level of economic development, and the Poor are so poor that they cannot afford to buy the good, even if the economy develops fully. Figure 6 shows the shape of the $D$ curve in this four-class economy, which is actually a step function. The dynamics can thus be analyzed by superimposing the $45^{\circ}$ line on this step function. It is easy to see that; 
If $I^{U}<a_{0}+A\left(N^{R}\right)$, then $\lim _{t \rightarrow \infty} Q(t)=N^{R}$,

If $I^{u} \geq a_{0}+A\left(N^{R}\right)$ and $I^{L}<a_{0}+A\left(N^{u}\right)$, then $\lim _{t \rightarrow \infty} Q(t)=N^{u}$;

If $I^{u} \geq a_{0}+A\left(N^{R}\right)$ and $I^{L} \geq a_{0}+A\left(N^{u}\right)$, then $\lim _{t \rightarrow \infty} Q(t)=N^{L}$.

These results are summarized in Figure 7.

The effects of some exogenous income redistribution can ready be seen from Figure 7. For example, suppose that, initially, the parameters are such that the economy is in Region I, given by Point $\mathrm{X}$ or by Point $\mathrm{Y}$. Then, imagine that some members of the Upper-middle class become Rich at the expense of the Poor. In Figure 7, the effect of this change is captured by an increase in $N^{R}$ and by a decline in $A\left(N^{R}\right)$, while neither $N^{U}$ nor $A\left(N^{U}\right)$ change. If the change is sufficiently small, it just means that a larger fraction of the households buy the good, simply because there are more Rich households in this economy. If the change is sufficiently large--how large depends on how close $\mathrm{X}$ or $\mathrm{Y}$ originally is to the line, $I^{U}=a_{0}+A\left(N^{R}\right)--$, it puts the economy into Region II (in the case of X) or into Region III (in the case of $Y$ ). Thus, every Upper-middle class family (in the case of $X$ ), or even every Lower-middle class family (in the case of Y), will eventually be able to enjoy the good. Figure 8 illustrates this possibility. This thought experiment thus suggests that the presence of a relatively large number of wealthy households helps the economy to develop, with the benefits of increased productivity trickling down from the Rich to the Upper-middle 
to the Lower-middle classes, while leaving the Poor behind. This arguably suggests one reason why the United States led the way in becoming a mass consumption society.

As a second thought experiment, consider redistributing income from the Upper-middle class to the Lower-middle class. Possible effects are illustrated by the arrows in Figure 7. The slopes of these arrows are equal to $n^{L} / n^{u}$. For the case indicated by the shorter arrow, the economy moves from II to III. This suggests the possibility that a larger fraction of the families will be able to enjoy the good as a consequence. Narrowing the income gap between the Upper and Lower middle classes helps the benefits of productivity gains trickle down all the way to the Lower-middle class. The longer arrow, however, suggests another possibility. In this case, the economy moves from II to I. The trickle-down process is cut short, because of wider income gaps between the Rich and the Uppermiddle class. Figure 9 illustrates the dynamics of the thought experience.

\section{The Case of $J=2$.}

Let us now consider the case, where $J=2$. Eq. (5) is now given by

$$
\dot{Q}_{1}=\delta_{1}\left\{D_{1}\left(Q_{1}\right)-Q_{1}\right\}
$$




$$
\dot{Q}_{2}=\delta_{2}\left\{D_{2}\left(Q_{1}, Q_{2}\right)-Q_{2}\right\}
$$

where $D_{1}\left(Q_{1}\right) \equiv 1-F\left(a_{0}+A_{1}\left(Q_{1}\right)\right) \geq D_{2}\left(Q_{1}, Q_{2}\right) \equiv 1-F\left(a_{0}+A_{1}\left(Q_{1}\right)+A_{2}\left(Q_{2}\right)\right)$. Figure 10 illustrates (9). The dynamics of $Q_{1}$ can be analyzed as a one-dimensional system, which has been discussed in the previous section. The dynamics of $Q_{2}$, on the other hand, depends on $Q_{1}$. As $Q_{1}$ increases monotonically from 0 to its (lowest) steady state level, $Q_{1}^{*}$, the curve $D_{2}\left(Q_{1}, Q_{2}\right)$ shifts up from $D_{2}\left(0, Q_{2}\right)$ to $D_{2}\left(Q_{1}^{*}, Q_{2}\right)$. Thus, not only the purchases of good 1 by the high-income households make it possible for the low-income households to buy good 1 through the trickle-down process. The purchase of good 1 by the low-income households, by reducing the price of good 1 further, allows the high-income households to buy good 2. It is this trickle-up process that transmits the productivity gains from one industry to another, generating the Flying Geese pattern.

One possible configuration of the phase diagram for the dynamical system (9) is illustrated in Figure 11a, which assumes that the $D_{1}$ curve intersects with the $45^{\circ}$ line three times, so that there are three steady state levels of $Q_{1}$. They are depicted by the three vertical lines in the phase diagram. It is also assumed that the $D_{2}$ curve does not intersect with the $45^{\circ}$ line, if $Q_{1}$ is equal 
to its value at the highest intersection of the $D_{1}$ curve with the $45^{\circ}$ line. ${ }^{11}$ As shown, there are multiple steady states, which form a lattice, as (P4) states. As (P7) states, for each unstable steady state, there are a pair of stable steady states that are connected with trajectories, one from above and one from below. The least element and the greatest element of the lattice are both stable steady states. Starting from $\left(Q_{1}, Q_{2}\right)=(0,0)$, the economy converges to the least element, as (P6) states. (The heavily barbed trajectory illustrates the convergence.) Because of the presence of this steady state, the economy cannot develop any further. In particular, it cannot reach the greatest element of the lattice.

Now, suppose that agricultural productivity improves, a decline in $a_{0}$, which shifts the $D_{1}$ curve up sufficiently that it now intersects only once with the $45^{\circ}$ line. After this change, the phase diagram looks as in Figure 11b. There is now a unique steady state, to which the economy monotonically converges. (Again, the heavily barbed trajectory illustrates the convergence.) The intuition should be easy to grasp. A high agricultural productivity, or a low food price, now enables more households to buy good 1, which helps to keep the trickle down process going further down to the lower income households. This change initially may have little impact on good 2. As the trickle-down process in good 1

\footnotetext{
${ }^{11}$ Figure 11a also assumes that the $D_{2}$ curve intersects with the $45^{\circ}$ line three times for an intermediate range of $Q_{1}$, which includes the low and middle steady state values of $Q_{1}$, but these are not crucial for the following discussion. It should also be noted that neither Figure 11a nor Figure 11b are not drawn "up to scale."
} 
continues and the price of good 1 keeps falling, however, the trickle-up process starts working. Thanks to the low price of good 1, the high-income households now start buying good 2, which triggers the trickle-down process in good 2.

Let us consider the case of four classes, as in the previous section, except that it is now assumed that $I^{R}>a_{0}+A_{1}(0)+A_{2}(0)$ and $I^{P}<a_{0}+A_{1}(1)$. That is, the Rich is so rich that they can afford to buy both goods, regardless of the level of economic development, and the Poor is so poor that they cannot afford to buy even good 1, even if the economy develops fully. Furthermore, let us assume that $A_{1}\left(N^{R}\right)<A_{1}\left(N^{L}\right)+A_{2}\left(N^{R}\right)$ and $A_{1}\left(N^{L}\right)<$ $A_{1}\left(N^{L}\right)+A_{2}\left(N^{U}\right)$. Then, there are six regions to distinguish, which are given by

If $I^{U}-a_{0}<A_{1}\left(N^{R}\right)$, then $\lim _{t \rightarrow \infty} Q(t)=\left(N^{R}, N^{R}\right)$.

If $A_{1}\left(N^{R}\right) \leq I^{U}-a_{0}<A_{1}\left(N^{U}\right)+A_{2}\left(N^{R}\right) ; I^{L}-a_{0}<A\left(N^{U}\right)$, then $\lim _{t \rightarrow \infty} Q(t)=\left(N^{U} ; N^{R}\right)$. If $A_{1}\left(N^{R}\right) \leq I^{u}-a_{0}<A_{1}\left(N^{L}\right)+A_{2}\left(N^{R}\right) ; I^{L}-a_{0} \geq A_{1}\left(N^{u}\right)$, then $\lim _{t \rightarrow \infty} Q(t)=\left(N^{L}, N^{R}\right)$. If $I^{u}-a_{0} \geq A_{1}\left(N^{u}\right)+A_{2}\left(N^{R}\right) ; I^{L}-a_{0}<A\left(N^{u}\right)$, then $\lim _{t \rightarrow \infty} Q(t)=\left(N^{u} ; N^{U}\right)$. If $I^{u}-a_{0} \geq A_{1}\left(N^{L}\right)+A_{2}\left(N^{R}\right) ; A_{1}\left(N^{u}\right) \leq I^{L}-a_{0}<A_{1}\left(N^{L}\right)+A_{2}\left(N^{u}\right)$, then $\lim _{t \rightarrow \infty} Q(t)=$ $\left(N^{L}, N^{u}\right)$.

If $I^{U}-a_{0} \geq A_{1}\left(N^{L}\right)+A_{2}\left(N^{R}\right) ; I^{L}-a_{0} \geq A_{1}\left(N^{L}\right)+A_{2}\left(N^{U}\right)$, then $\lim _{t \rightarrow \infty} Q(t)=\left(N^{L}, N^{L}\right)$,

which is summarized in Figure 12. 
Not surprisingly, the effects of some forms of income redistribution in this case is similar in many ways to the case of $J=1$, discussed in the previous section. For example, if some members of the Upper-middle class become Rich at the expense of the Poor, the economy could move from Region I to II, from II to IV, from I to III, from III to V or from III to IV. All these possibilities suggest that the presence of a relatively large number of wealthy households could help the economy to develop, with the benefits of increased productivity trickling down from the Rich to the Uppermiddle to the Lower-middle classes, while leaving the Poor behind.

As in the case of $J=1$, redistributing income from the Upper-middle class to the Lower-middle class, by narrowing the gap between the two middle classes, could help the trickle-down process to reach the Lower-middle class. This occurs if the transfer of income moves the economy from II to III (or from V to VI). Or, by widening the gap between the Rich and the Upper-middle class, the transfer could block the trickle-down process from reaching the Upper-middle class. This occurs if the change moves the economy from II to I (or from V to III).

With $J=2$, however, there is a new possibility, which is not present in the case of one industry. The Upper-middle class could gain from redistributing its income to the Lower-middle class. This somewhat paradoxical effect occurs if the redistribution moves the economy from II to $\mathrm{V}$ or to VI. By narrowing the gap between the two middle classes, this 
transfer of income helps the trickle-down process in good 1 to reach the Lower-middle class. The purchase of good 1 by the Lower-middle class helps to reduce the price of good 1, which now allows the Upper-middle class to buy good 2, which would not be affordable to them without the transfer being made. Due to this trickle-up mechanism, the Upper-middle class ends up gaining from giving some of their income away to the Lowermiddle class.

\section{Robustness}

In the model presented above, many strong assumptions are used to simplify the analysis. For example, learning-by-doing is industry-specific and bounded. All the households have the same order of priority over the goods. The assumed utility function has the strong form of ParetoEdgeworth complementarity. This section explains why these assumptions are not critical for much of the results obtained above.

\subsection{Inter-industry Spillover of Learning-by-Doing}

The case for learning-by-doing spillovers across industries might be weaker than the case for learning-by-doing spillovers across different generations of products within an industry, which has previously been 
analyzed by Stokey (1988) and many others. Nevertheless, it is hard to deny any presence of such interindustry spillovers. In the previous analysis, interindustry spillovers were excluded from the model, not because they are empirically implausible nor because their presence would make the analysis harder. It was rather because their presence would obscure the role of demand complementarity in transmitting productivity gains from one industry to another.

It is easy to see that introducing interindustry spillovers make no qualitative difference. For example, no change in the analysis is needed if $A_{j}(Q)$, now a function of $Q$, is increasing in $\left(Q_{1}, \ldots, Q_{j}\right)$ and independent of $\left(Q_{j+1}, \ldots, Q_{J}\right)$. Then, the system remains recursive and cooperative. Of course, there is little reason to believe that learning-by-doing spillovers only from a lower-indexed industry to a higher-indexed one, given that the order is defined according to the household's priority. If $A_{j}(Q)$ is increasing in all the elements, the system is no longer recursive, only cooperative. Note, however, that (P1), (P3), (P4), (P6) do not require the system to be recursive. In particular, cooperativeness alone ensures (P6). That is, a series of industries take off one after another, and they all grow monotonically until the economy reaches the least element of the set of steady states, which has a lattice structure. The analysis of section 4 is, of course, entirely independent of this assumption (because there is only one industry). It is also straightforward to extend the analysis of section 5 for the nonrecursive case. 


\subsection{Different Ordering of Goods Across Households.}

Most results reported in section 3 will carry over even when households differ in their ordering of goods, as long as each household has a welldefined priority over the goods (that is, the order in which goods are consumed is independent of the relative prices over the relevant range). Then, the dynamical system remains cooperative, although it is no longer recursive. As explained in $6 A$, cooperativeness alone ensures (P6). That is, a series of industries take off one after another, and they all monotonically converge to the lowest steady state.

There might be, however, one significant change in the qualitative feature of the dynamics. Some industries may catch up with and move ahead of the industries that took off earlier. To see this, imagine that there are three manufacturing goods, $J=3$, and two types of households. The first type wants good 1 most and good 2 least; the second type wants good 2 most and good 1 least. Good 3 is everyone's second choice. In such a case, it is easy to see the possibility that the penetration rates of all the three goods take off one after another, but the last one to take off, 3, will catch up and move ahead of 1 and 2 .

The analysis of section 4 is, of course, entirely independent of this assumption (because there is only one industry). The analysis of section 5 
would be hopelessly complicated, if households were allowed to be different in preferences. Indeed, the analysis of income distribution loses much of the operational meaning, if the income is not the only source of heterogeneity.

\subsection{Alternative Specifications of the Preferences}

The assumed utility function in the above model has the strong form of Pareto-Edgeworth complementarity, which implies that, if some good is not consumed, the households benefit nothing from consuming any higher indexed good. This specification was used, because it helps to preserve the ordering of goods, independent of the relative prices. This assumption can be dropped without any significant change in the analysis, as long as we impose some additional restrictions on technology that limit the range of the equilibrium relative prices.

To see this, suppose that the utility function is now given by $U=1+$ $\sum_{j=1}^{J} b_{j} x_{j}+\eta l$ for $c>1$, which has no Pareto-Edgeworth complementarity. The value of consuming good $j$ is simply $b_{j}>0$, regardless of whether other goods are consumed. Let us assume that $b_{j}$ is decreasing in $j$. If $p_{j}$ is nondecreasing in $j$, then all the households would buy lower-indexed goods first. To ensure this, we need to make some restrictions on the 
technology side. One way of doing it is to assume that both $A_{j}(\bullet)$ and $\boldsymbol{\delta}_{j}$ are independent of $j$. Then, if $Q_{1}(t) \geq Q_{2}(t) \geq \ldots \geq Q_{J}(t)$, then $C_{1}(t) \geq C_{2}(t) \geq \ldots \geq$ $C_{J}(t)$, which implies that $Q_{1}(s) \geq Q_{2}(s) \geq \ldots \geq Q_{J}(s)$ and hence $C_{1}(s) \geq C_{2}(s) \geq$ $\ldots \geq C_{J}(s)$ for all $s \geq t$, because the speed of learning depends only on the market size. In other words, the region where the lower-indexed goods are cheaper then the higher-indexed goods, $\left\{Q \in[0,1]^{J} \mid Q_{1} \geq Q_{2} \geq \ldots Q_{J}\right\}$, is positively invariant. Therefore, once the economy enters this region, the households always buy lower-indexed goods first. For example, if the economy starts at $Q(0)=(0,0, \ldots, 0)$, then the aggregate demand for each good $j$ can be represented by eq. (1) for the entire future. Hence, the analysis would go through without any change, even though no Pareto-Edgeworth complementarity exists across consumer goods. What is essential for the results is demand complementarity, or the Hicks-Allen complementarity, i.e., a lower price of one good increases demand for other goods.

\subsection{Unbounded Learning-By-Doing}

In the model presented above, the development process stops eventually. Merely allowing for infinitely many industries does not generate unbounded growth; growth must stop, as long as learning-by-doing in each industry is bounded. The assumption of bounded learning-by-doing may be plausible if we consider only narrowly defined sets of products. As 
argued by Stokey (1988) and Lucas (1993), however, the industry can learn how to produce "new and improved" products from manufacturing experiences of old products. The existence of such learning-by-doing spillovers across different generations of products make learning-by-doing at the industry level unbounded even when the scope of learning in each product is bounded.

The above model can be modified to allow for unbounded learning-bydoing and hence for unbounded growth. Suppose that there are infinitely many industries, $j=1, \ldots, \infty$. The unit labor cost in each industry is given by $A_{j}\left(Q_{j}\right)$, where $A_{j}$ is a decreasing function and satisfies $A_{j}(\infty)=0$. The dynamics of $Q_{j}(t)$ is now governed by the initial condition, $Q_{j}(0) \geq 0$, as well as by $\dot{Q}_{j}(t)=B_{j}\left(C_{j}(t), Q_{j}(t)\right)$. The dynamical system is cooperative, if $B_{j}$ is increasing in the first argument (i.e., more production means faster learning) and decreasing in the second argument (i.e., knowledge depreciates). The boundary condition, $B_{j}(0,0) \geq 0$, ensures that the system is well-defined over $\Re_{+}^{\infty}$. Now suppose that $B_{j}\left(1, Q_{j}\right)>0$ for all $Q_{j}>0$ for all $j$ $=1, \ldots, \infty$. (That is, the market size is potentially large enough to sustain productivity gains forever.) Then, there exists unbounded paths along which $\lim _{t \rightarrow \infty} Q_{j}(t)=\infty$ and $\lim _{t \rightarrow \infty} C_{j}(t)=1$ for all $j=1, \ldots, \infty$. The existence of such unbounded growth paths, however, does not guarantee that the economy grows forever for any initial condition. If the set of steady states, $S \subset \Re_{+}^{\infty}$, is nonempty, the cooperativeness of the system ensures that $S$ is a 
lattice and the economy converges to its least element, if the initial condition is sufficiently close to the origin. Only when $S$ is empty, the economy achieves unbounded growth. ${ }^{12}$ The interesting question is then what restriction on income distribution ensures that $S$ is empty, and hence that unbounded growth becomes attainable by the rise of a mass consumption society.

\section{Concluding Remarks.}

This paper developed a model to understand mechanisms behind the rise of mass consumption societies. The development process depicted in the model follows the Flying Geese pattern, in which a series of industries takes off one after another. Central to the analysis is a two-way causality between productivity improvement and the rise of a mass consumption society. As productivity improves in these industries, the prices of consumer goods go down. As a result, an increasingly large number of consumer goods become affordable to an increasingly large number of households, and spread from high-income to low-income households. This in turn generates larger markets for consumer goods, which leads to further improvement in productivity.

\footnotetext{
${ }^{12}$ Note that the system is now defined over $\mathfrak{R}_{+}^{\infty}$ instead of $[0,1]^{J}$, hence Tarski's fixed-point theorem is not applicable, and $S$ can be empty.
} 
Whether such two-way causality generates virtuous cycles of productivity gains and expanding markets depends critically on the distribution of income across households. For example, it was shown that income distribution should be neither too equal nor too unequal. If it is too equal, the process does not begin. If it is too unequal, it stops prematurely. Apart from the two extreme cases of income distribution, the effects of income distribution turn out to be quite subtle. This is because, for the benefits of improved productivity to trickle down and/or to trickle up across households, income needs to be distributed in certain ways. For example, it was shown that an income transfer from the Upper-middle to the Lowermiddle classes helps the benefits to spread to the Lower-middle class in certain cases. In other cases, it prevents the benefits from reaching even to the Upper-middle class.

Needless to say, the above model can be extended in many directions. Let us discuss some useful extensions, as well as possible difficulties that may arise from such extensions.

The above model has only one factor of production, labor. Introducing additional factors helps to endogenize income distribution through changes in relative factor prices. (Such extension is also useful when introducing international trade in this model, as will be discussed later.) Imagine that there are two factors, land and labor. Food (and possibly some lower-indexed consumer goods) is more land-intensive than (higher- 
indexed) consumer goods. Furthermore, suppose that the land ownership is highly concentrated, but the labor endowments are not. In this case, the distribution of income becomes more equal, as the economy develops and the demand shifts towards higher indexed goods, thereby driving up the wage rate faster than the land rent. One interesting possibility may arise in such a model. At the beginning of development, the uneven distribution of the land ownership ensures the presence of enough rich households, which helps to trigger the process. And once the economy takes off, the wage/rent ratio adjusts to ensure the rise of a mass consumption society with more even distribution of income.

The model may be extended to incorporate international trade. The important issue here is the nature and scope of dynamic increasing returns. Suppose that learning-by-doing in production spillovers freely across borders, so every producer in every country can learn from experiences of other producers in the same industry in the world. (To simplify matters, let us restrict ourselves to the case of no interindustry spillovers.) Then, the closed economy model presented above may be applied to the global economy without any modification. For example, the case of four classes discussed in sections 4 and 5 may be reinterpreted as a model of the world economy, which consists of four countries, where the population is homogeneous within each country, but countries differ in their endowments of human capital. When the scope of learning-by-doing spillovers is global, the only additional (but by no means trivial) issue is the 
pattern of international trade, which should reflect the cross-country differences in the distribution of income.

When the scope of spillovers is not global, one needs to be careful about the exact nature of dynamic increasing returns. For example, suppose that dynamic increasing returns are due to country-specific consumption externalities, so the price of consumer good in one country depends on the discounted cumulative consumption in that country. Such externalities may arise if the effort required to use a good declines, as the country's consumers accumulates more experiences using the good, or if the presence of some network externalities at the national level facilitates the use of the good. In a two-country world, this situation can be viewed as the case, where there are $2 J$ consumer goods and two types of households care for two disjoint sets of $J$ consumer goods. The dynamics is thus described by two J-dimensional cooperative dynamical systems, which are linked by the balanced trade condition. This linkage could potentially make the relation between two dynamical systems competitive (in the sense of Hirsch). Such a possibility could arise if the rise of a mass consumption society in one country and the resulting shifts in the composition of demands lead to a deterioration of the terms of trade for the other country. If the negative effect of the terms of trade deterioration is large enough, it could prevent the rise of a mass consumption society there. To rule out this possibility, it is necessary to impose some restrictions on the model. One way of doing it is to ensure that both countries produce 
food in equilibrium. Then, the terms of trade remains constant, and the world economy can be described by two independent cooperative systems. Of course, this is not to say that it is uninteresting to consider the possibility that the rise of a mass consumption society in one country prevents others from becoming mass consumption societies. It simply means that the mathematical technique used above have limited power in analyzing such a case.

Let us now consider the case where the dynamic increasing returns are due to country-specific learning by doing in production, so that the only location of production, but not the location of consumption, matters. As is well known, when learning-by-doing in production is country-specific, the initial pattern of comparative advantage tends to perpetuate. Once the lock-in effects of country-specific learning-by-doing take place, however, the continuation of the dynamics of this world economy should resemble the dynamics of the closed economy model (with multiple factor extensions). To see this, imagine that there are two countries, Home and Foreign, and Home has established its comparative advantages in certain industries, and Foreign has established its own in others. This world economy can be modeled by an extension of the above model, which incorporates two factors and two types of households. Two factors are called Home labor and Foreign labor. Home households are endowed only with Home labor and Foreign households only with Foreign labor. Furthermore, we interpret that the goods for which Home (Foreign) 
establishes its comparative advantages are the goods that use only Home (Foreign) labor. Therefore, analytically, the case of country-specific learning-by-doing in production can be dealt with by multiple factor extensions of the above model. There is an additional interesting issue to consider, however. The benefits of expanding markets fall disproportionately on those countries that happened to establish their comparative advantages in higher-indexed goods, because they specialize in the production of goods whose income elasticities of demand are higher than the average. ${ }^{13}$

The analysis in this paper was made simple because of the static nature of the household's decision problem. Allowing for saving and borrowing or for intertemporal substitution of consumption certainly makes the model more realistic, but it also introduces complications that would obscure the basic mechanisms identified in this paper. For example, allowing for saving could potentially make the equilibrium indeterminate, thereby opening up the possibility of escaping the poverty trap through selffulfilling expectations, the possibility discussed by Matsuyama (1991b) in a different context. Taking into account the durability of goods would generate an incentive for the households to delay their purchases until the prices come down. This would introduce another reason why the spread

\footnotetext{
${ }^{13}$ Matsuyama (2000) explored this issue in detail in a model of international trade which has similar demand structures with the present model, but with exogenous technological changes.
} 
of consumer goods may be gradual, thereby obscuring the role of the nondegenerate distribution of income. ${ }^{14}$ This is not to deny the desirability of incorporating these factors into the model. However, the tractability would require to limit the analysis to the case of one industry, which means that we have no hope for generating the Flying Geese pattern, and even with one industry, it would be necessary to impose many stringent restrictions on functional forms.

A similar remark can also be made on the specification of dynamic increasing returns. The critical feature of the present model is that the speed of productivity improvement responds to the market size. Learningby-doing with complete spillover across competitive producers is the simplest way of capturing the feature without introducing any intertemporal decision on the production side. In reality, of course, productivity improvement comes also from R\&D activities. It is not clear, however, whether modeling dynamic increasing returns due to $R \& D$, instead of learning-by-doing, would generate any additional insights that merit complications that arise from the intertemporal nature of innovations. ${ }^{15}$

\footnotetext{
${ }^{14}$ Jovonovic and Lach (1989) analyzed how an incentive for firms to wait for the price to come down affects the diffusion of new technologies.

${ }^{15}$ See Zweimüller (1999) for an attempt to analyze the effect of income distribution on growth by incorporating what he calls hierarchic preferences in an otherwise standard R\&D-based endogenous growth model.
} 
Finally, in this paper the distribution of income (or more generally purchasing power) across households is treated as the primitive of the model. In particular, the households are not allowed to set up lotteries. Once the possibility of lotteries is introduced, many questions posed in this paper, such as "what is the role of income distribution in the rise of a mass consumption society?" or "what are the effects of income transfer?," themselves become ill-defined. On a positive note, the model presented in this paper should be a useful building block for analyzing general equilibrium implications of lotteries and other modes of consumer finances. 


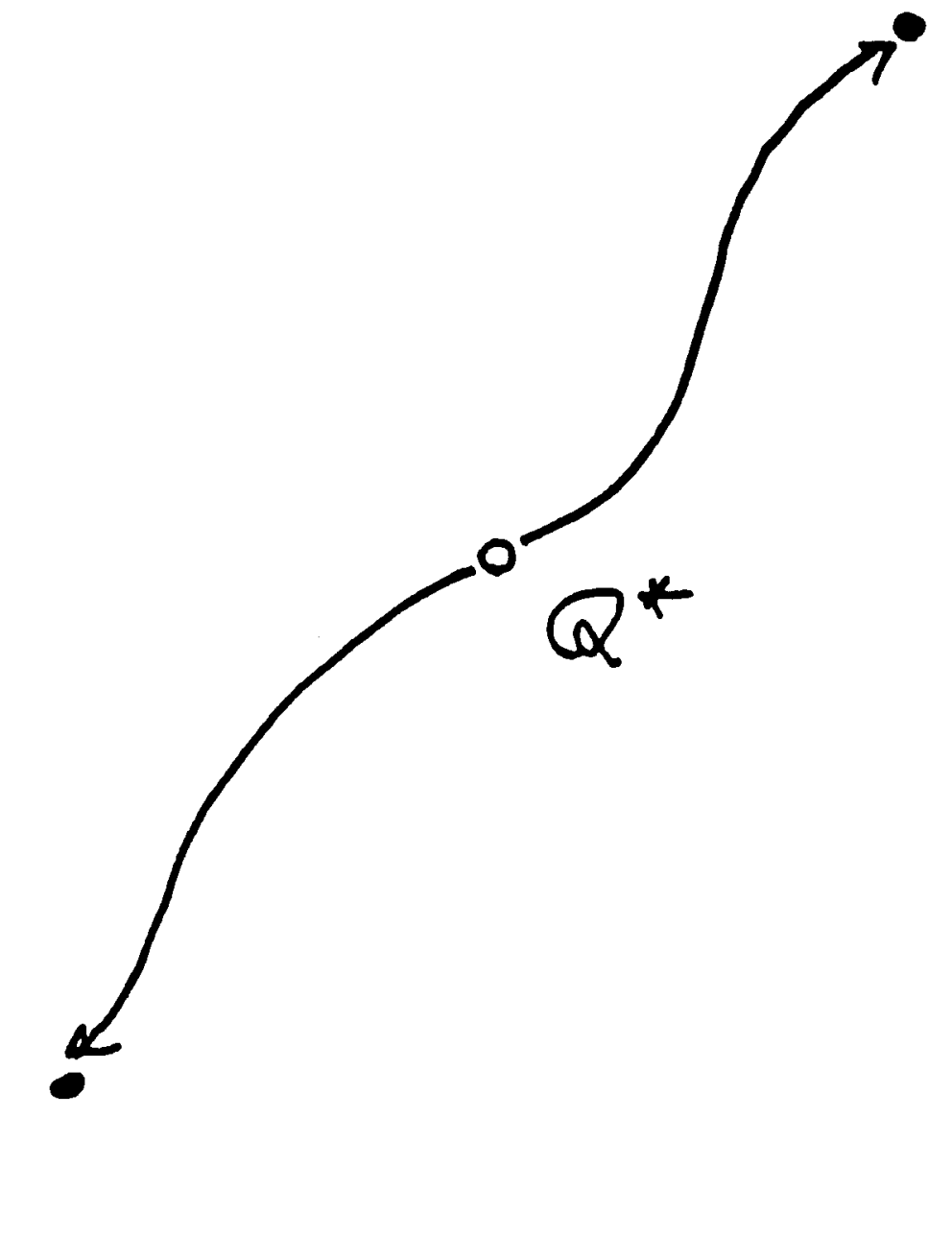




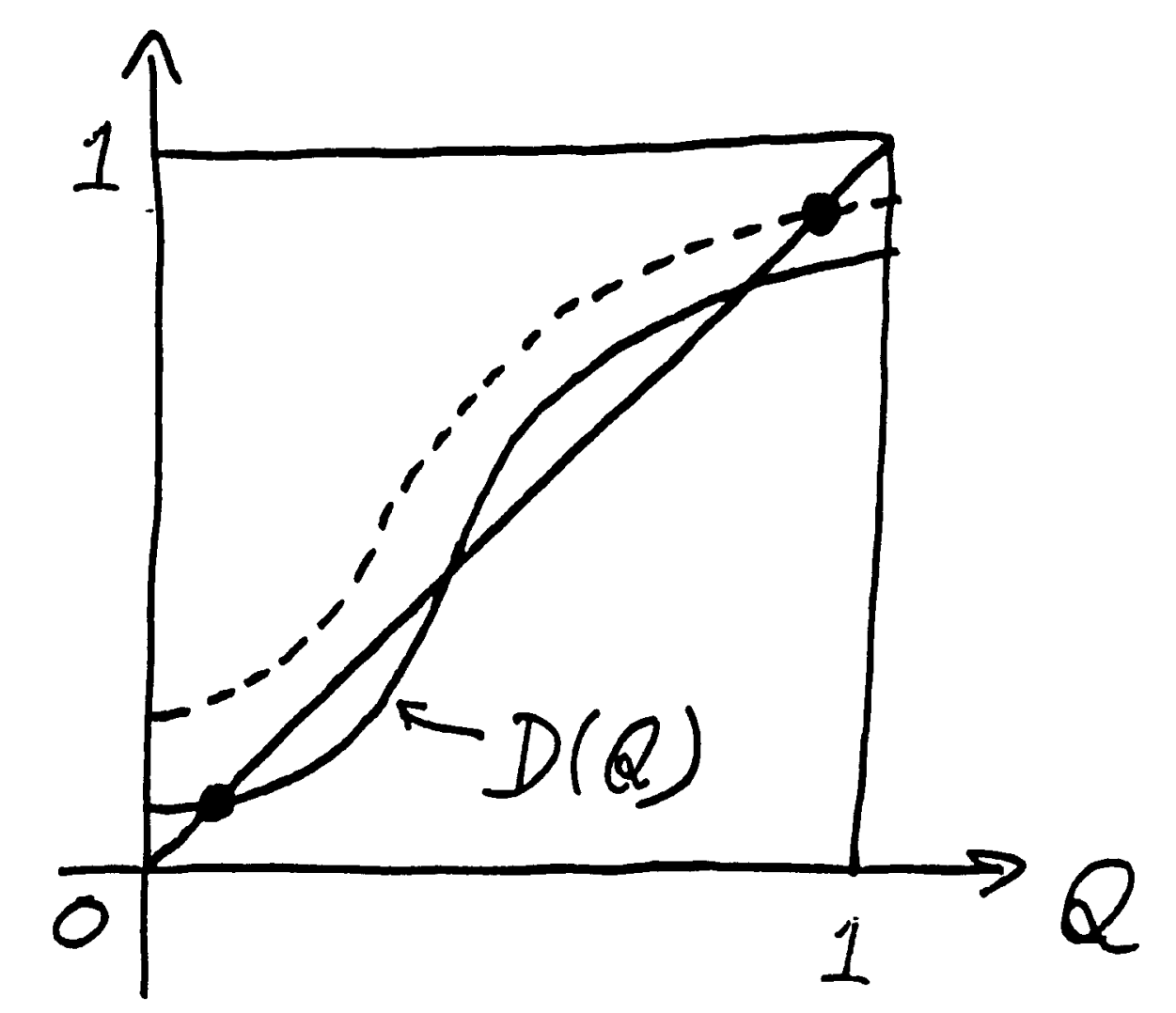

Fig, 3

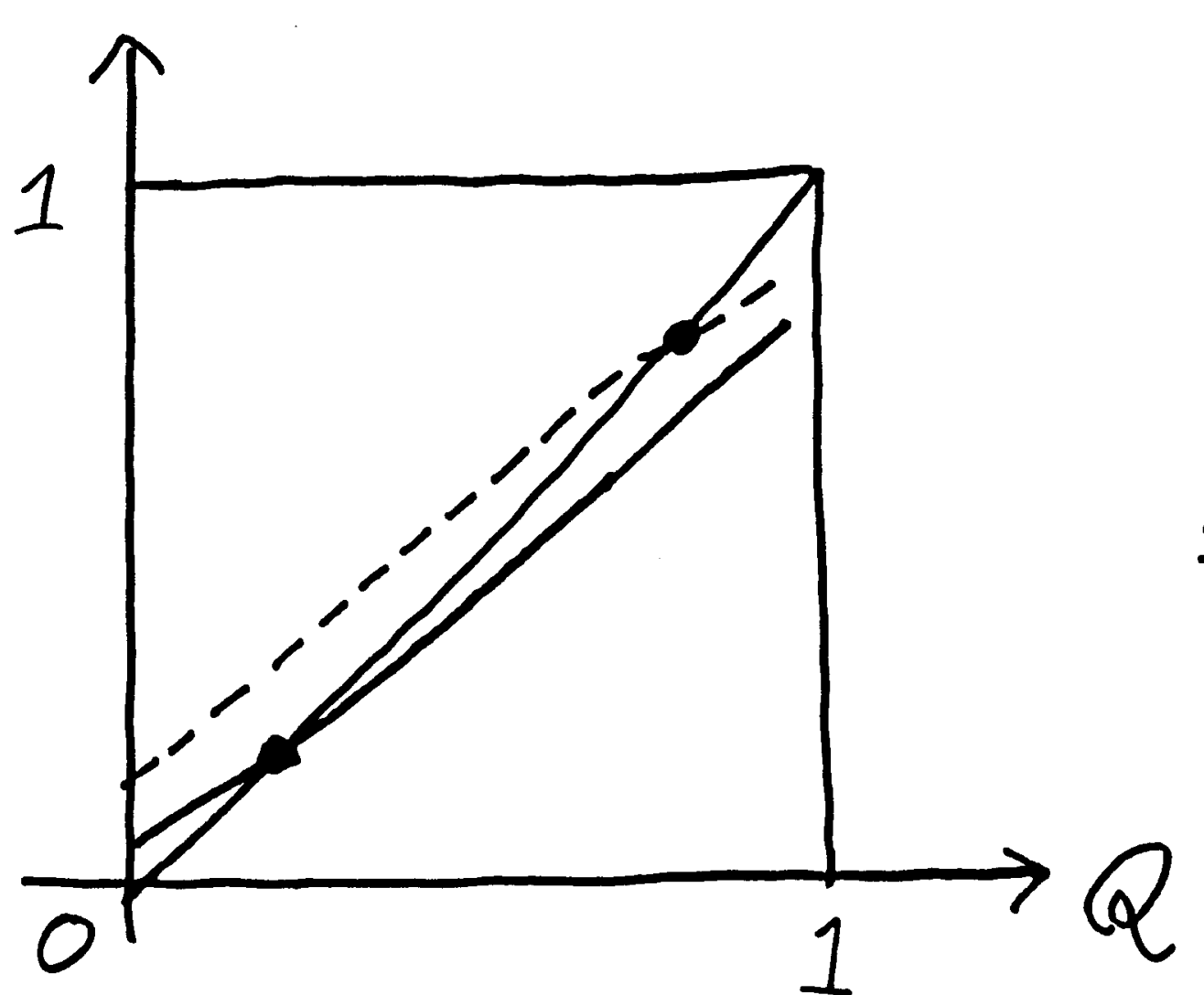

Fig, 4 


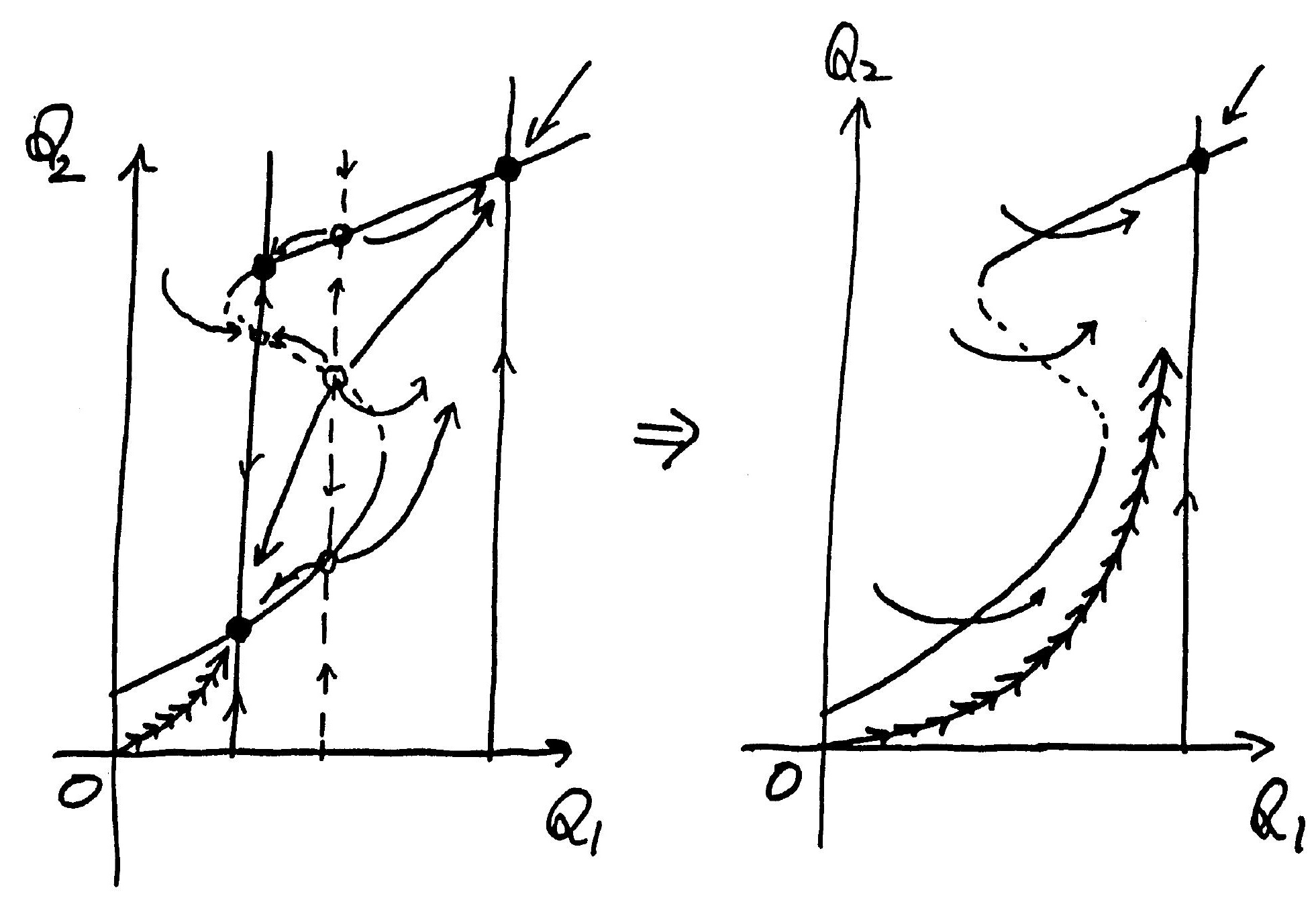

F字 $11 a$

Fig. 116 


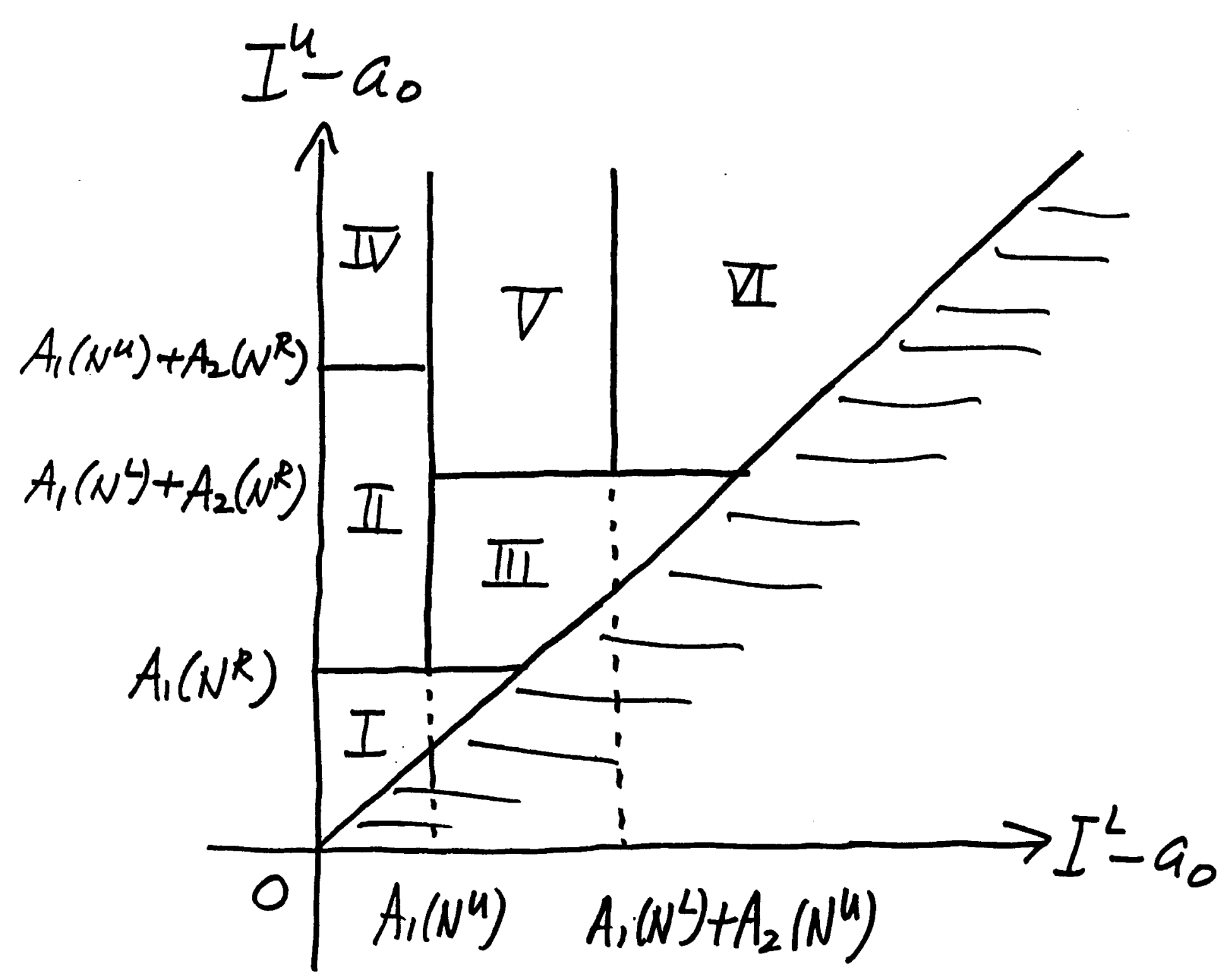

Fig. 12 


\section{References:}

Akamatsu, Kaname, "A Theory of Unbalanced Growth in the World Economy," Weltwirtschaftliches Archive, 86, 1961, 196-217.

Baland, Jean-Marie, and Debraj Ray, "Why does Asset Inequality Affect Unemployment?: A Study of the Demand Composition Problem," Journal of Development Economics, 35, 1991, 69-92.

Fourastié, Jean, Les Trente Glorieuses: ou La Révolution Invisible de 1946 à 1975, Paris, Fayard, 1979.

Hirsch, M. W., "System of Differential Equations which are Competitive or Cooperative I: Limit Sets," SIAM Journal of Mathematical Applications, 13, 1982, 167-179.

Jovanovic, Boyan, and Saul Lach, "Entry, Exit and Diffusion with Learning by Doing," American Economic Review, 79 (4), September 1989, 690-699.

Katona, George, The Mass Consumption Society, McGraw-Hill, New York, 1964.

Kosai, Yutaka, and Yoshitaro Ogino, Nihon Keizai Tenbo, Tokyo, Nihon Hyoron Sha, 1980. The English translation, The contemporary Japanese economy, New York, M.E. Sharpe, 1984.

Lucas, Robert E. Jr., “Making a Miracle,” Econometrica, March 1993, 251-272.

Matsuyama, Kiminori, "Agricultural Productivity, Comparative Advantage, and Economic Growth," Journal of Economic Theory, 58, 1991, 317-334. a) 
Matsuyama, Kiminori, "Increasing Returns, Industrialization and Indeterminacy of Equilibrium," Quarterly Journal of Economics, May 1991, 106, 617-650. b)

Matsuyama, Kiminori, "A Ricardian Model with a Continuum of Goods under Nonhomothetic Preferences: Demand Complementarities, Income Distribution, and North-South Trade," Journal of Political Economy, December 2000, forthcoming.

Murphy, Kevin M., Andrei Shleifer, and Robert Vishny, "Income Distribution, Market Size, and Industrialization," Quarterly Journal of Economics, August 1989, 537-564.

Rostow, Walt Whitman, The Process of Economic Growth, 2nd ed. Oxford, Clarendon Press, 1960.

Schama, Simon, The Embarrassment of Riches: An Interpretation of Dutch Culture in the Golden Age, New York: Knopf, 1987.

Smith, Hal L., Monotone Dynamical Systems: An Introduction to the Theory of Competitive and Cooperative Systems, Mathematical Surveys and Monographs: Vol. 41, Providence, American Mathematical Society, 1995.

Stokey, Nancy L., "Learning by Doing and the Introduction of New Goods," Journal of Political Economy, 96, 1988, 701-717.

Tarski, Alfred, "A Lattice-Theoretical Fixpoint Theorem and Its Applications," Pacific Journal of Mathematics, 1955, 5, 285-309.

Uchino, Tatsuro, Sengo Nihon Keizai Shi (The Postwar Japanese Economic History), Tokyo, Kodansha, 1978.

Zweimüller, Josef, "Schumpertarian Entrepreneurs Meet Engel's Law: The Impact of Inequality on Innovation-Driven Growth," University of Zurich, 1999. 